\title{
A hora da mudança
}

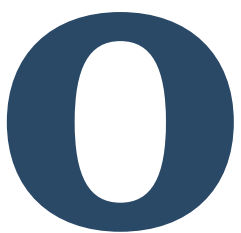

que fazer quando sua empresa precisa passar por uma mudança, de grande ou de pequeno porte? Quais são os caminhos a serem tomados equais os obstáculos a serem enfrentados? Este artigo sugere um modelo para a gestão de mudanças planejadas, o V.I.A.R.M.A., que se baseia na tese de que o processo transformacional pode ser realizado de cima para baixo, sustentando-se em dois pilares distintos: liderança egestão. Somentea conjugação dessas duas dimensões de ação pode garantir o êxito da mudança planejada.

por Arménio Rego Universidade de Aveiro e Miguel Pina e Cunha Universidade Nova de Lisboa

Processo planejado. Duas visões estreitamente relacionadas predominam em livros e teorias sobre processos de mudança. A primeira corresponde à idéia de que a mudança é um processo que pode/deve ser planejado. A segunda dita que a gestão da mudança é algo definido inicialmente no topo, para só então percorrer os diversos níveis e meandros da organização. Embora o processo como um todo não esteja, como veremos, isento de dificuldades e riscos, procuraremos descrevê-lo de forma a que esses percalços possam ser minimizados e, se possível, eliminados.

Digamos, por exemplo, que a diretoria da empresa procure introduzir uma política de comunicação interna menos 
hierarquizada e mais reticular, ou que então busque incutir entre os empregados a orientação permanente para a inovação de produtos. Há também a possibilidade de que a diretoria tente "inverter a pirâmide", colocando no "topo" os agentes operacionais que asseguram a qualidade do serviço ao cliente, posicionando na "base" - retaguarda - os gestores e pessoal de apoio, cuja incumbência é garantir a boa atuação dos operacionais. Os diretores podem decidir criar e implementar um código de ética que norteie as atuações cotidianas dos funcionários na relação com os diversos stakeholders da organização - clientes, fornecedores e público em geral ou, ainda, substituir uma cultura de "emprego para toda a vida" por uma cultura de "empregabilidade". Em todos esses casos ilustrativos, prepondera a idéia de que a mudança é um processo planejado. $\mathrm{N}$ ão só. Essa perspectiva concebe 0 processo como algo que nasce na alta gerência, para depois sedisseminar pelo resto da empresa. A premissa básica éa de que compete aos gestores conduzir a mudança de forma que a organização se adapte às efetivas características do ambiente organizacional, sem sacrificar a possibilidade de ajustamento a diferentes condições futuras.

Um modelo que representa claramentea mudança planejada foi defendido por J. P. Kotter em seu recente livro Leading change. Sua tese aplica-se sobretudo a mudanças de maior envergadura, mas também cria possibilidades para transformações de menor porte. A seqüência que examinaremos constitui uma concepção voluntarista, atribuindo ao ápice estratégico da empresa a responsabilidade pela determinação do caminho - desenhado para que os diversos níveis da hierarquia possam percorrêlo. Há oito etapas que os gestores devem se-

\section{Quadro 1: Os oito passos da mudança planejada}

Estabelecer um sentido de urgência

Criar uma poderosa equipe dirigente

Desenvolver visão e estratégia

Estabelecer uma comunicação eficaz da visão

Remover obstáculos e passar à ação

Gerar ganhos de curto prazo

Consolidar ganhos e produzir mais mudança

Ancorar novas abordagens na cultura da organização
A análise do mercado e das realidades competitivas deve conduzir à identificação e discussão de crises reais e potenciais, bem como das principais oportunidades.

É importante que todos os membros da organização sejam imbuídos de um espírito dinâmico - isto é, que adquiram consciência da necessidade de mudança e não se permitam levar pela inércia.

A construção de uma equipe com poder suficiente para pôr a mudança em marcha é essencial. Equipes fracas ou sem representatividade não são capazes de remover obstáculos.

A próxima etapa consiste em articular uma visão forte (compreensível, atraente e realizável), que ajude a direcionar o esforço de mudança e inspire a ação dos colaboradores.

Passam então a ser definidas as estratégias que permitam alcançar essa visão.

A nova visão e as respectivas estratégias devem ser comunicadas continuamente e por todos os meios possíveis.

A equipe dirigente deve funcionar como um modelo de ação para os funcionários - suas ações devem ser coerentes com seu discurso.

Devem ser removidos os obstáculos à mudança, alteradas as estruturas e os sistemas que a dificultem, e encorajada a aceitação do risco e das ações heterodoxas.

Devem ser reforçados / recompensados os comportamentos consistentes com a nova visão e as estratégias correspondentes.

Deve ser assegurado 0 alcance de ganhos de curto prazo e recompensados os colaboradores que os facilitem. Caso contrário, os atores organizacionais podem adquirir sentimentos de descrença diante da mudança.

A credibilidade gerada pela obtenção de resultados deve ser usada para mudar todos os aspectos da organização que não se conformam à nova visão.

0 projeto deve ser constantemente revigorado com a introdução de novos temas e objetivos.

A cultura organizacional deve preservar e reforçar as novas maneiras de pensar e agir.

Enquanto a mudança não tiver penetrado na cultura da empresa, as celebrações de vitória podem ser precipitadas - podendo haver retrocessos no processo de transformação.

Fonte: Kotter, J. P. Leading change. Boston : Harvard Business School Press, 1996. 
guir se almejam ser bem-sucedidos (Quadro 1). As primeiras quatro etapas ajudam a confrontar o status quo organizacional. As três seguintes permitem a introdução de novas práticas. E a última infunde a mudança na cultura da organização. A primeira fase - remoção da antiga lógica de atuação - prepara o terreno para a segunda - introdução da nova lógica - , e a terceira promove a consolidação da mudança.

Não se deve queimar etapas. A tese sustenta que a seqüência precisa ser observada para que surta o efeito desejado. Segundo Kotter, uma análise cuidadosa das histórias de sucesso revela duas verdades fundamentais. Em primeiro lugar, as mudanças bem-sucedidas tendem a aderir a esse processo em várias fases seqüenciais que geram poder e motivação suficientes para acabar com as fontes de inércia. Em segundo lugar, a eficácia do processo depende, em considerável medida, da qualidade da liderança - e não apenas da excelência da gestão.

Modelo para a mudança. 0 modelo V.I.A.R.M.A., aqui proposto, assemelha-se bastante à proposta de Kotter e compreende seis etapas: visão, implementação, ativação, reconhecimento, monitoração/controle e apoio (Figura 1). Apresenta a vantagem de oferecer simplicidade e proporcionar uma associação nítida entre as fases do processo e a relevância dos papéis de liderança e de gestão.

A visão, a ativação e 0 apoio estão diretamente relacionados com a liderança. A implementação, a monitoração / controle e o reconhecimento representam o processo de gestão. A divisão entre os processos de gestão e de liderança tem sido alvo de amplacontrovérsia. Aqui, propomos sinteticamenteque a liderança é um processo mais transformacional, de longo prazo e afetivo, enquanto a gestão é mais "fria", racional, controladora e de curto prazo (Quadro 2). Emboradistintos, esses processos secomplementam: as empresas precisam de ambos para enfrentar os desafios da mudança permanente.

Eis o significado de cada uma das seis dimensões do modelo V.I.A.R.M.A.:

- A visãoéo processo fundamental dessemodelo. Deve representar uma imagem coerentedo futuro - confiável, realizável, clara, consistente, atraente e eficazmente comunicada (Q uadro 3). É ela que inspira os esforços dos membros da organização e dá orientação para as estratégias, as políticas e as ações diárias.

- A implementação compreende os planos estratégicos, os planos de mais curto prazo, os orçamentos e a gestão de cada projeto específico. Traduzem a visão em elementos mais específicos, tendo em vista sua realização. Predomina aqui 0 processo de gestão.

- A ativação consiste em assegurar que os membros da organização - e outros stakeholders - compreendam a visão e a mudança nela embutida, apóiem-nas ese empenhem em sua implementação. Alguns autores sugerem que amudança passa pela participação e pela articulação de uma visão que reflita os desejos e val ores das pessoas. Esse vértice do modelo está especialmente associado à liderança.

- O reconhecimento incorpora as ações destinadas a reconhecer e incentivar as pessoas envolvidas no processo - especialmente as mais empenhadas no sucesso da mudança e/ou que mais possam contribuir para seu êxito. Há vários tipos deações possíveis. As recompensas materiais / financeiras - por exemplo, aumento salarial e promoção - são um bom recurso, embora os prêmios simbólicos - como um elogio público - possam ser mais eficazes para certas pessoas e em determinadas situações. 0 processo de gestão impera nessa área, especialmente devido à lógica transacional com a qual se identifica.

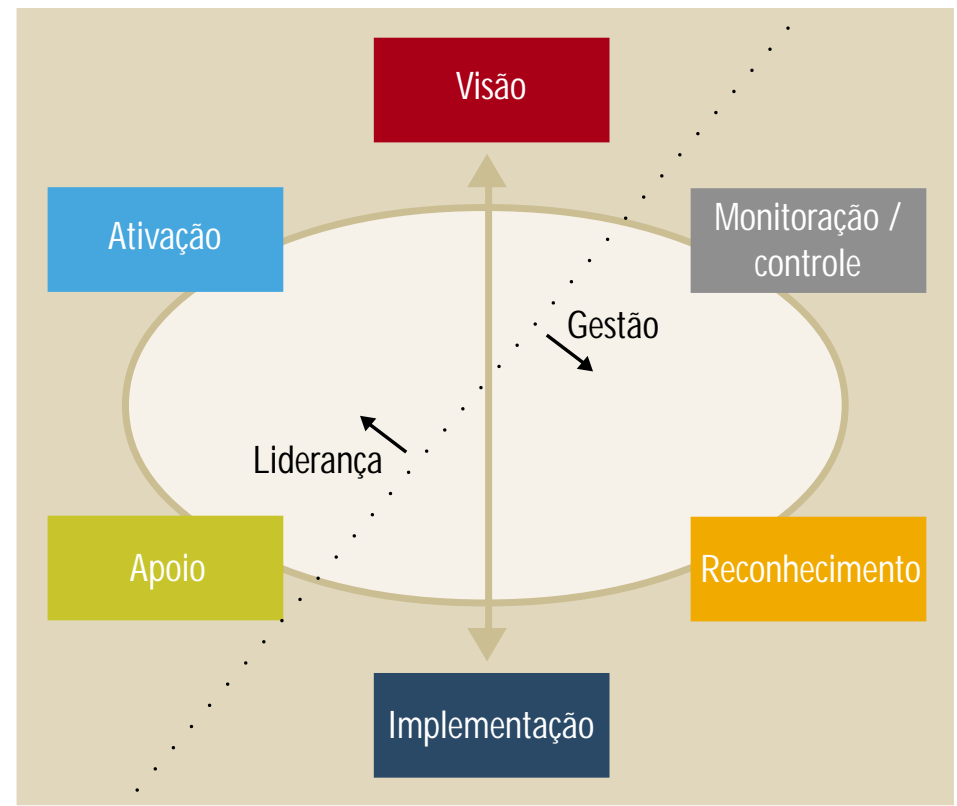

Figura 1: 0 modeloV.I.A.R.M.A.

Fonte: adaptada de Hussey, D. E. How to manage organizational change. London : Kogan Page, 1995. 
- A monitoração / controle assegura que o processo esteja no caminho correto. Implica que as ações sejam tomadas a tempo, que as reorientações de rumo sejam formuladas e concretizadas, que os desvios sejam corrigidos e que os erros sejam sanados. Processos de gestão são os aqui indicados.

mentação é a concretização da visão; todo o processo exige que as pessoas sejam motivadas para concretizar a mudança, que sejam apoiadas, que os sucessos sejam reconhecidos; e, por fim, por meio da monitoração / controle, garante-se que o processo siga a trilha apropriada.

Note-se a necessária

\section{A eficácia do processo de transformação}

\section{depende, em considerável medida, da qualidade}

\section{da liderança - e não apenas da excelência da gestão.}

- 0 apoio está muito associado ao reconhecimento, mas não se esgota nele. Representa as ações em que o líder inspira as pessoas a superar a si próprias, transmite-lhes expectativas de desempenho elevado, incute-lhes confiança, encoraja-as em momentos de dificuldade e descrença. É essencial que o líder sejaíntegro egenuíno. Trata-se deum vértice claramente alicerçado no processo de liderança.

Visão holística. As seis dimensões do modelo estão intimamente associadas - não sendo recomendável tomá-las como uma seqüência monolinear. De qualquer modo, podemos esboçar uma concatenação: a visão inicia o processo; a impleuma implementação eficaz, garantida pelos processos de gestão. Além disso, o apoio sócio-afetivo - da liderança - interage com os mecanismos de reconhecimento transacional - por exemplo, financeiros - para estimular nas pessoas níveis mais elevados decomprometimento. Em suma, podemos dizer que a liderança exige gestão para que a sobrevivência no curto prazo esteja assegurada, e que a gestão requer liderança para que a organização supere as fontes de inércia e assegure seu futuro.

Nem tudo são flores. A tese segundo a qual a mudança deve ser realizada de cima para baixo predomina entre consultores e executivos, mas isso não torna sua materialização

\section{Quadro 2: Liderança vs. gestão: dois processos distintos mas complementares}

\begin{tabular}{|l|l|}
\hline LIDERANÇA & GESTÃo \\
\hline Focalizada no futuro & Focalizada no presente \\
\hline Mudança & Estabilidade, ordem e previsibilidade \\
\hline Quadro orientador: visão & Quadro orientador: cumprimento das regras \\
\hline Empowerment dos colaboradores & Controle dos colaboradores \\
\hline Simplificação & Complexidade \\
\hline Intuição & Razão e lógica \\
\hline Relacionamento & Autoridade \\
\hline Orientação para a sociedade & Orientação para a organização \\
\hline A mudança reflete propósitos mútuos de líderes e seguidores & $\begin{array}{l}\text { Coordenação de atividades para produzir e vender bens e/ ou } \\
\text { serviços que reflitam os propósitos da empresa }\end{array}$ \\
\hline $\begin{array}{l}\text { Estabelecimento de uma direção / visão, alinhamento das pes- } \\
\text { soas com essa visão, motivação e inspiração dos membros orga- }\end{array}$ & $\begin{array}{l}\text { Orçamento, organização, estruturação, controle e resolução de } \\
\text { problemas }\end{array}$ \\
\hline nizacionais & \\
\hline
\end{tabular}


prática menos sujeita a obstáculos. Vejamos alguns deles:

- Devido a resistências, o que é planejado nem sempreéimplementado. Em conseqüência, o plano acaba sendo adulterado - e, assim, aumentam os riscos de que não responda adequadamente aos desafios com que se defronta a empresa.

- Os tomadores de decisão podem se ver sem os conhecimentos e a informação necessários para a compreensão das particularidades locais - aumentando, então, os riscos de a mudança tomar caminhos errados.

- A luta política gerada na arena organizacional pode anular a eficácia dos planos, boicotá-los ou descaracterizá-los.

- A almejada introdução de mudanças pode se inspirar em projetos desucesso importados de outras organizações, não se adequando à realidade específica que caracteriza a empresa.

Duplo comando. Os modelos aqui expostos não procuram esconder esses riscos e desvantagens - antes se destinam precisamente a preveni-los e a geri-los. É importante que não

\section{A liderança exige gestão para que} a sobrevivência no curto prazo esteja assegurada. A gestão requer liderança para que a organização supere as fontes de inércia e garanta seu futuro.

os tomemos como remédios para todos os males, mas como roteiros genéricos que incorporam os el ementos fundamentais da gestão bem-sucedida de mudanças planejadas.

Eles chamam, ainda, a atenção para a necessidade de conciliar a liderança e a gestão. Diversos autores e vários exemplos concretos sugerem a dificuldadeem conciliá-las na mesma pessoa, daí surgindo a tese que defendea dupla liderança- alguém exercendo o papel de gestão e outro o de liderança. Assim, é provável que o modelo V.I.A.R.M.A., para ser realmente bemsucedido, não requeira somente dois processos, mas também dois parceiros que os executem em complementaridade.

\section{Quadro 3: Características de uma visão eficaz}

Imaginável (o que a empresa será no futuro)

Desejável / atraente

Ambiciosa

Praticável, realizável, realista e crivel

Enraizada na realidade econômica

Focalizada e clara

Internamente consistente

Incutida nas convicções do líder e/ou da equipe que encabeça a mudança

Flexível

Comunicável e compreensivel
A visão faculta uma imagem palpável do que a organização e suas atividades serão no futuro.

A visão apela aos interesses de longo prazo dos diversos stakeholders - clientes, empregados, fornecedores. A visão deve ser suficientemente ambiciosa para impelir as pessoas a saírem de suas "rotinas confortáveis". Se as metas compreendidas na visão não se mostrarem realizáveis e realistas, os diversos stakeholders perdem confiança e não se empenham em sua concretização.

A visão deve considerar as tendências fundamentais da vida econômica e empresarial, a globalização e as linhas de progresso tecnológico.

A visão não pode ser vaga - sob pena de as pessoas não se espelharem nela, nem nela se nutrirem como guia orientadora.

Os elementos da visão devem ser congruentes. As contradições internas podem diminuir a credibilidade e o pendor inspirador.

É fundamental que, por seus atos e discursos, os líderes da mudança demonstrem que estão confiantes na visão e em seu sucesso.

Uma boa visão é suficientemente clara para motivar a ação, mas flexível o bastante para permitir a iniciativa individual e a adoção de respostas que se ajustam às condições dinâmicas da evolução.

A visão deve ser facilmente transmitida, explicável em poucos minutos - sob pena de não ser compreendida pela grande diversidade de destinatários. 